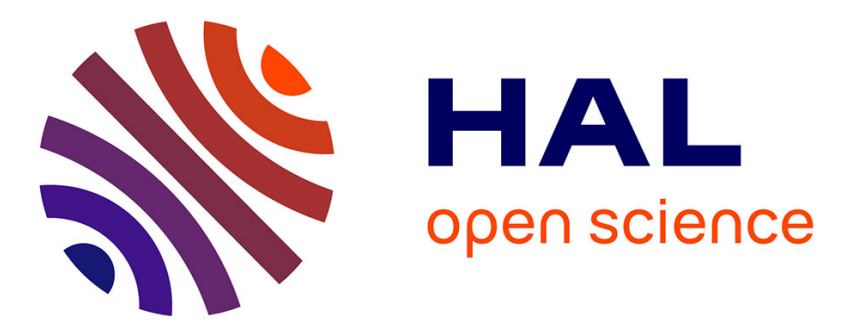

\title{
Chiral Phosphoric Acid-Catalyzed Enantioselective Construction of 2,3-Disubstituted Indolines
}

Wei-Yang Ma, Coralie Gelis, Damien Bouchet, Pascal Retailleau, Xavier

Moreau, Luc Neuville, Géraldine Masson

\section{- To cite this version:}

Wei-Yang Ma, Coralie Gelis, Damien Bouchet, Pascal Retailleau, Xavier Moreau, et al.. Chiral Phosphoric Acid-Catalyzed Enantioselective Construction of 2,3-Disubstituted Indolines. Organic Letters, 2021, 23 (2), pp.442-448. 10.1021/acs.orglett.0c03947 . hal-03238222

HAL Id: hal-03238222

https://hal.science/hal-03238222

Submitted on 27 Jul 2021

HAL is a multi-disciplinary open access archive for the deposit and dissemination of scientific research documents, whether they are published or not. The documents may come from teaching and research institutions in France or abroad, or from public or private research centers.
L'archive ouverte pluridisciplinaire HAL, est destinée au dépôt et à la diffusion de documents scientifiques de niveau recherche, publiés ou non, émanant des établissements d'enseignement et de recherche français ou étrangers, des laboratoires publics ou privés. 


\title{
Chiral Phosphoric Acid Catalyzed Enantioselective Construction of 2,3-Disubstituted Indolines.
}

\author{
Wei-Yang Ma, ${ }^{\dagger *}$ Coralie Gelis,${ }^{\dagger}$ Damien Bouchet, ${ }^{\dagger}$ Pascal Retailleau, ${ }^{\dagger}$ Xavier Moreau,${ }^{\dagger}$ Luc Neuville,${ }^{\dagger}$ \\ and Géraldine Masson*广
${ }^{\dagger}$ Institut de Chimie des Substances Naturelles, CNRS UPR 2301, Université Paris-Sud, Université Paris-Saclay, 1, av. de la Terrasse, Gif-sur-Yvette 91198 Cedex, France
*Institut Lavoisier Versailles, UMR CNRS 8180, Université de Versailles-St-Quentin-en-Yvelines, Université Paris-Saclay, Versailles, France \\ Supporting Information Placeholder
}
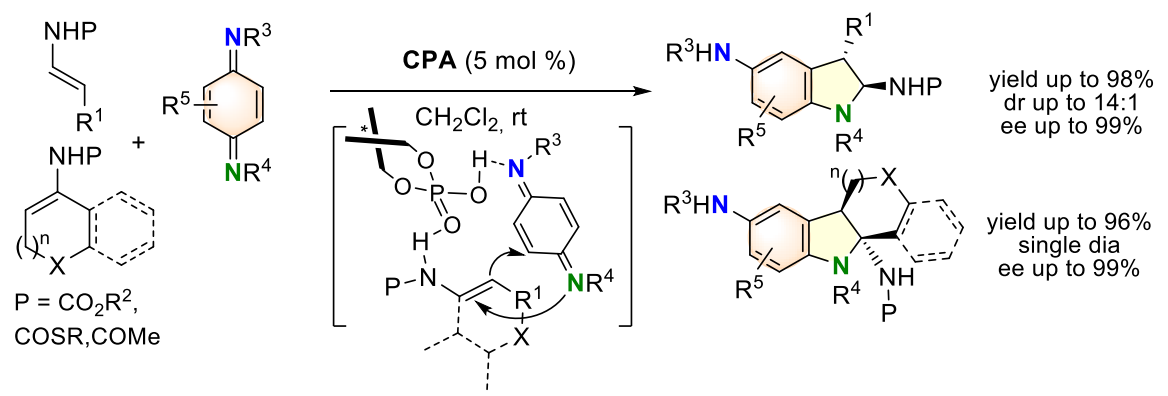

\begin{abstract}
Highly enantio- and regioselective selective $(3+2)$ formal cycloaddition of $\beta$-substituted ene- and thioenecarbamates as well as cyclic enamides with quinone diimides catalyzed by a BINOL- and SPINOL-derived phosphoric acid has been reported. A wide variety of 2-amino 2,3-disubtituted indolines, including polycyclic ones, were prepared in generally high yields (up to $98 \%$ ) with moderate to complete diastereoselectivities and in most cases excellent enantioselectivities (up to 99\% ee).
\end{abstract}

Chiral 2,3-disubstituted indolines are privileged heterocyclic rings frequently encountered in various natural bioactive alkaloids (such as (-)-physostigmine, $(+)$-aspidospermidine and pircrinine, Figure 1$)^{1}$ and biologically active drugs (such as pentopril and relcovaptan). ${ }^{2}$ In addition, they have been successfully employed as chiral auxiliaries and organocatalysts in asymmetric synthesis. ${ }^{3}$ As a result, several asymmetric catalytic approaches have been established for the construction of indoline rings. ${ }^{4}$ Despite these elegant achievements, the development of novel asymmetric synthetic routes of 2,3disubstituted indolines is still highly desirable.

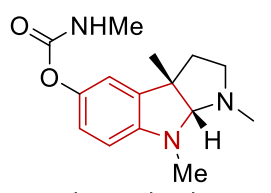

physostigmine

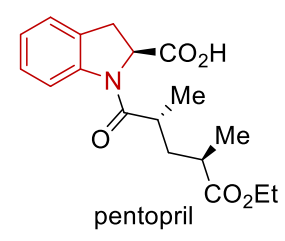

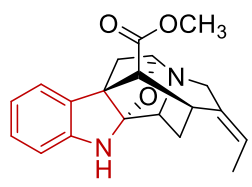

picrinine dospermine

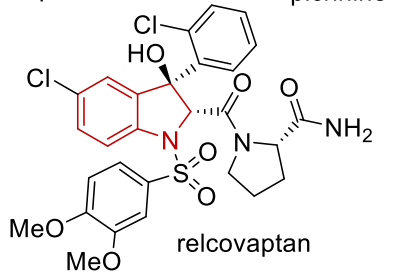

Figure 1. Representative bioactive indolines and its derivatives.

$(3+2)$ Cycloaddition is one the of the most convergent methods for the synthesis of five-membered heterocycles fused with aromatic rings. ${ }^{5}$ More specifically, $(3+2)$ formal cycloaddition of quinones (or quinone monoimines) with electron rich alkenes affords a convenient synthesis of dihydrofurans, oxygen analogue of indolines. ${ }^{4 \mathrm{r}, 6,7}$ The aza variant ${ }^{8}$ of this reaction using quinone diimides ${ }^{9}$ to produce indolines has not been well explored. Furthermore, in these examples, there are few methods to synthesize 2,3-disubstituted indolines. ${ }^{8 \mathrm{~d}, \mathrm{e}}$ Indeed, while the chemistry of quinones diimides is rich, their unfriendly preparation (often relying on lead tetraacetate), their sensitivity towards hydrolysis of the carbon-nitrogen double bond, their redox properties leading to self-rearomatization or oxidative coupling ${ }^{10}$ hampers their wide use. ${ }^{11}$ In this context, it is not surprising, that catalytic enantioselective transformation involving quinone diimides remains extremely rare. ${ }^{12}$ To the best of our knowledge, only one example of enantioselective, cycloaddition involving $p$-quinone diimides has been recently reported. ${ }^{4 \mathrm{x}}$ We describe here the development of chiral

Scheme 1. Catalytic enantioselective formal (3+2) cycloaddition with quinone derivatives.

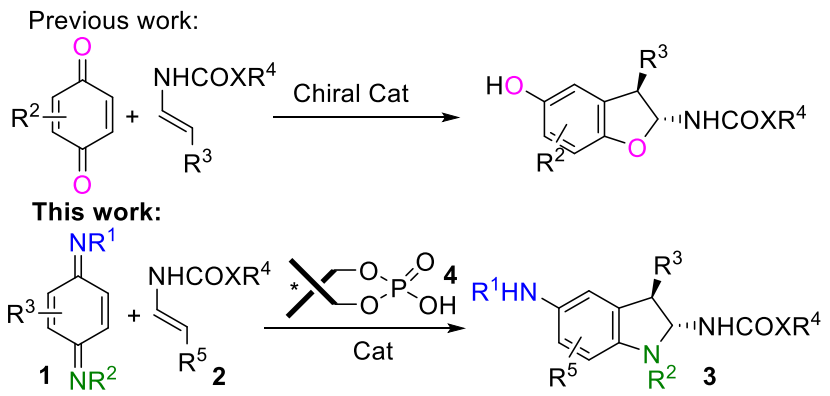


phosphoric acid (CPA)-catalyzed enantioselective $(3+2)$ formal cycloaddition of quinone diimides and enecarbamates providing a simple and practical access to 2,3-disubstituted indolines (Scheme 1).

We have previously reported a CPA-catalyzed enantioselective $(3+2)$ cycloaddition reactions of quinones with ene- and thioenecarbamtes. ${ }^{7 \mathrm{a}}$ The reaction has a broad scope, offering 2,3-disubstituted 2-amino-2,3-dihydrobenzofurans with high enantioselectivity. The diastereoselectivity was highly dependent on the protecting groups on the nitrogen atom of the dipolarophiles: the thiocarbamates gave high selectivity in favor of trans isomer while the reactions with the enecarbamates were poorly diastereoselective. On the basis of our previous work, ${ }^{7 \mathrm{a}, 13}$ we initially investigated the reaction between $p$-quinone di-p-toluenesulfonimide (1a) and $(E)$ thioenecarbamate $\mathbf{2 a}$, in presence of a CPA catalyst (Table 1). ${ }^{14}$

Table 1. Optimization of catalytic enantioselective synthesis of indolines. ${ }^{a}$

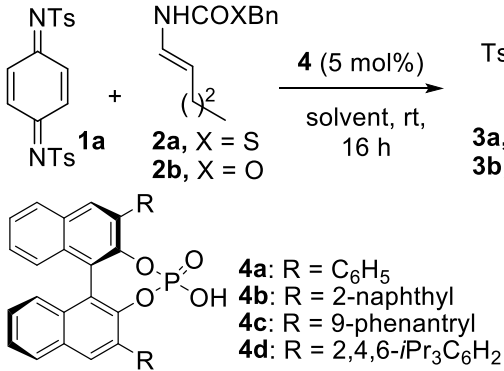

(R)-BINOL

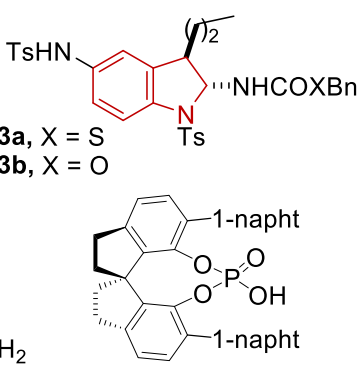

$(R)$-SPINOL $\quad 4 \mathrm{e}$

$\begin{array}{lllllll}\text { entry } & \text { cat } & \mathbf{2} & \text { solvent } & \begin{array}{l}\text { yield } \\ (\%)^{b}\end{array} & \mathrm{dr}^{\mathrm{c}} & \text { ee (\%) })^{d, e} \\ 1 & \mathbf{4 a} & \mathbf{2 a} & \text { toluene } & 93 & 5: 1 & (+) 34 \\ 2 & \mathbf{4 b} & \mathbf{2 a} & \text { toluene } & 91 & 5: 1 & (+) 32 \\ 3 & \mathbf{4 c} & \mathbf{2 a} & \text { toluene } & 66 & 5: 1 & (+) 43 \\ 4 & \mathbf{4 d} & \mathbf{2 a} & \text { toluene } & 92 & 5: 1 & (+) 98 \\ 5 & \mathbf{4 e} & \mathbf{2 a} & \text { toluene } & 91 & 5: 1 & (-) 98 \\ 6 & \mathbf{4 d} & \mathbf{2 a} & \mathrm{CH}_{2} \mathrm{Cl}_{2} & 98 & 6: 1 & (+) 98 \\ 7 & \mathbf{4 e} & \mathbf{2 a} & \mathrm{CH}_{2} \mathrm{Cl}_{2} & 93 & 6: 1 & (+) 98 \\ 8 & \mathbf{4 d} & \mathbf{2 a} & \mathrm{CH}_{2} \mathrm{Cl}_{2} & 72^{\mathrm{f}} & 6: 1 & (+) 98 \\ 9 & 4 \mathbf{2 a} & \mathrm{CH}_{2} \mathrm{Cl}_{2} & 93^{\mathrm{f}} & 6: 1 & (-) 98 \\ 10 & 4 \mathbf{2 b} & \mathrm{CH}_{2} \mathrm{Cl}_{2} & 94 & 6: 1 & (-) 94\end{array}$

${ }^{a}$ General condition: 1a $(0.10 \mathrm{mmol}), \mathbf{2 a}(0.12 \mathrm{mmol})$ and Cat $(5 \mathrm{~mol} \%)$ in solvent $(0.1 \mathrm{M})$ at $\mathrm{rt}$ for $16 \mathrm{~h} .{ }^{b}$ Yield of isolated pure product after chromatography. ${ }^{c}$ Determined by ${ }^{1} \mathrm{H}$ NMR. ${ }^{d}(+)$ refers to absolute $(2 S, 3 S)$ configuration, $(-)$ refers to $(2 R, 3 R)$ configuration, assigned by analogy to X-ray crystal-structure analysis of 3c (see Supporting Information). Determined by HPLC analysis on a chiral stationary phase. ${ }^{f}$ With $2.5 \mathrm{~mol} \%$ of 4.

Pleasingly, the desired 2-amino-2,3-disubstituted indolines 3a was obtained in high yield albeit with moderate selectivity by using $5 \mathrm{~mol} \%$ of $\mathbf{4 a}$ as the catalyst in toluene at room temperature for $16 \mathrm{~h}$ (entry 1). To increase both diastereo and enantioselectivity of this reaction, a series of CPA catalysts 4 were evaluated (entries 1-5). The catalyst $4 \mathbf{d}$ bearing 2,4,6triisopropylphenyl groups at the 3,3'-position of BINOL, as well as 4e from SPINOL having a 1-naphthy group at the $6,6^{\prime}$ position $4 \mathbf{e}$ provided the desired product in much better enantioselectivity $(98 \%$ ee, entries 4 and 5$)$ but the diastereomeric ratio was not significantly influenced by catalyst choice. A slight increase in the trans-diastereoselectivity was observed with $\mathrm{CH}_{2} \mathrm{Cl}_{2}$ as solvent (entry 6 vs 4 ). On one side, reducing catalyst loading of $\mathbf{4 d}$ to $2.5 \mathrm{~mol} \%$ leads to a reduction in yield (entry 8 vs 6). On the other side, no activity loss was noted when $2.5 \mathrm{~mol} \%$ of $\mathbf{4 e}$ was used (entry 9 vs 7 ), thereby providing conditions that were selected for further investigations When we conducted the reaction with the enecarbamate $\mathbf{2 b}$, the corresponding cycloadduct $\mathbf{3 b}$ was formed in similar diastereo- and enantioselectivity than $\mathbf{2 a}$, thus indicating (contrary to our previous work) ${ }^{7 \mathrm{a}}$ that the protecting group of $\mathbf{2}$ did not have too much influence on the stereoselectivity. Other solvents such as $\mathrm{CHCL}_{3}, \mathrm{CH}_{3} \mathrm{CN}$, THF and toluene were evaluated to improve the diastereoselectivity

Scheme 2. Scope of the enantioselective $(3+2)$ formal cycloaddition. ${ }^{a-d}$

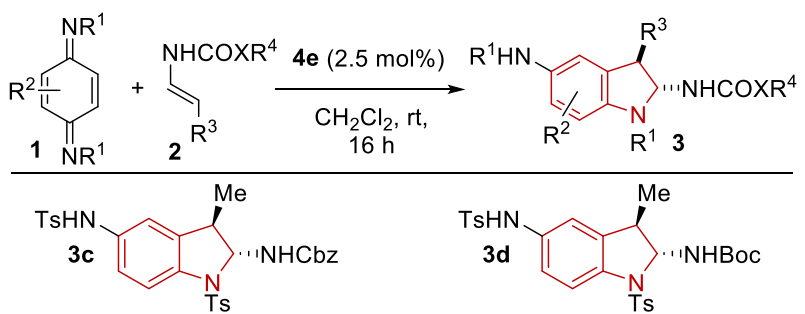

$93 \%, 3: 1 \mathrm{dr} 99 \%$ ee

$95 \%, 3: 1 \mathrm{dr}, 99 \%$ ee $\mathrm{e}^{\mathrm{e}}$

$88 \%, 3: 1 \mathrm{dr}, 99 \% \mathrm{ee}^{e, f}$

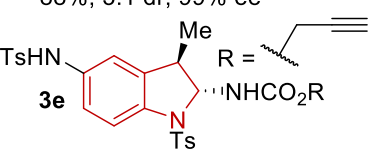

$83 \%, 4: 1 \mathrm{dr}, 99 \%$ ee

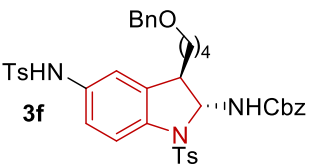

$83 \%, 4: 1 \mathrm{dr}, 99 \%$ ee $\mathrm{Ph}$<smiles>CC(=O)Nc1ccc2c(c1)C(Cc1ccccc1)[C@H](NC(=O)Cc1ccccc1)N2C</smiles>

$88 \%, 6: 1 \mathrm{dr}, 98 \%$ ee<smiles>CC(C)[C@H]1c2cc(N[AsH])ccc2N([AsH2])[C@H]1NC(=O)O</smiles>

$95 \%, 6: 1 \mathrm{dr}, 99 \%$ ee<smiles>CC(C)[C@H]1c2cc(N[As])ccc2N([As])[C@H]1NC(=O)Cc1ccccc1</smiles>

$79 \%, 14: 1 \mathrm{dr}, 89 \%$ ee

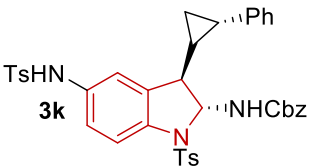

$93 \%, 10: 1 \mathrm{dr}, 95 \%$ ee<smiles>CC(C)(C)N[C@H]1Nc2ccc(Nc3ccccc3)cc2[C@H]1C(=O)O</smiles>

$91 \%, 6: 4 \mathrm{dr}, 40 \%$ ee $95 \%, 8: 1 \mathrm{dr}, 96 \% \mathrm{ee}^{e}$

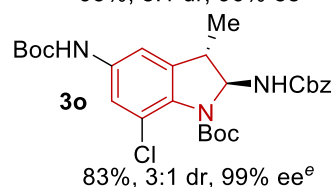

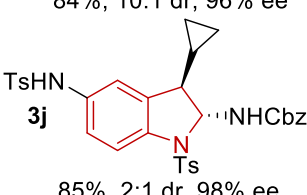

$85 \%, 2: 1 \mathrm{dr}, 98 \%$ ee<smiles>C[C@H]1c2cc(NS(C)(=O)=O)ccc2N(C)[C@H]1NC(C)(C)C</smiles>

$88 \%, 4: 1 \mathrm{dr}, 99 \%$ ee

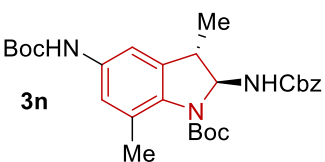

$92 \%, 6: 1 \mathrm{dr},>99.9 \% \mathrm{ee}^{e}$

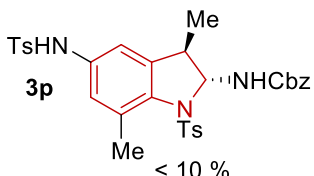

${ }^{a}$ General condition: $1(0.10 \mathrm{mmol}), 2(0.12 \mathrm{mmol})$ and $4 \mathrm{e}(2.5 \mathrm{~mol} \%)$ in $\mathrm{CH}_{2} \mathrm{Cl}_{2}(0.1 \mathrm{M})$ at $\mathrm{rt}$ for $16 \mathrm{~h}$. ${ }^{b}$ Yield of isolated pure product after chromatography. ${ }^{c}$ ee Determined by HPLC analysis on a chiral stationary phase. ${ }^{d}$ dr determined by ${ }^{1} \mathrm{H}$ NMR. ${ }^{e}$ With 5 mol\% of $4 \mathbf{d d} .{ }^{f}$ With $1 \mathrm{mmol}$ of 2 . 
(See supporting information). Although a higher diastereomeric ratio was only found in $\mathrm{THF}(8: 1)$, yield was reduced substantially. ${ }^{15}$ All attempts to separate the diastereomers were unsuccessful.

Having identified the optimum conditions (Table 1, entry 9), we explored the generality of the reaction by employing different enecarbamates. In general, the reactions worked well for selected protecting groups bonded to the nitrogen of $\mathbf{2}$, including benzyloxy, prop-2-yn-1-yl and tert-butoxy carbamates. A range of linear $\beta$-substituted ene- and thioenecarbamates $\mathbf{2}$ reacted successfully, affording the corresponding 2-aminoindolines $\mathbf{3 c - 3} \mathbf{k}$ in high yields with excellent enantioselectivities. The additional benzyl ether functional group was well tolerated on enecarbamate providing cycloadduct $\mathbf{3 f}$ with good enantioselectivity. The enecarbamate bearing an ethyl-benzene side chain also furnished a high level of enantioselectivity (3g: 99\% ee). To our satisfaction, ene- and thioenecarbamate substituted by isopropyl group at the $\beta$ position furnished compound $\mathbf{3 h}$ and $\mathbf{3 i}$ with an excellent diastereoselectivity $(10: 1$ to $14: 1)$ possibly revealing a significant substrate control effect. However, slight decrease of enantioselectivity was observed with the thioenecarbamate compared to the enecarbamate. Surprisingly, performing the reaction with a unsusbtituted cyclopropyl side chain instead of an isopropyl group, lead to a drastic reduction in diastereoselectivity but enantioselectivity was kept high (3jj, 2:1 dr, ee: 98\%). Only trace of product was formed with enecarbamate bearing phenyl group at the $\mathrm{C}-2$ position (data not shown). Presence of an enantiopure predefined chiral center on the enecarbamate moiety did not interfere with catalyst induction. Hence, compound 3k was prepared in 93\% yield and in $95 \%$ ee with a satisfactory $4: 1$ diastereoselectivity relatively to the 2 newly formed chiral centers.

Alternative quinone diimines bearing various protecting group and substituents were also investigated. On the one hand, dimethylsulfonimide uneventfully participated in the cycloaddition, giving 31 with $99 \%$ ee. On the other hand, carboxybenzyl or acyl bis-protected diimines were not suitable partner for the transformation (data not shown). ${ }^{16}$ It was however possible to move away from sulfonyl-type protection as Boc-protected quinone diimine delivered compound $\mathbf{3 m}$ in excellent yield. Regarding to enantioselectivity, SPINOLderived CPA 4e was far from ideal for such precursors. A brief optimization revealed that $\mathbf{4 d}$ was suitable for high enantioselective induction (See Supporting Information). These Boc protected imines also tolerated substituent on the quinone core. As such, methyl and chlorine were fully tolerated delivering compound $\mathbf{3 n}$ and $\mathbf{3 o}$ as single regioisomers in good yields and enantioselectivities. This is particularly noteworthy as corresponding methyl bis-tosyl imine was reluctant in forming compound $\mathbf{3 p}$. ${ }^{16}$ Boc quinone diimides having stronger electron withdrawing group such as $\mathrm{NO}_{2}$ group were not stable enough to perform the reaction (data not shown). ${ }^{16}$ We also demonstrated that the reaction could be easily performed on a $1.0 \mathrm{mmol}$ scale, preparing cycloadduct $\mathbf{3 c}$ with $\mathbf{4 d}$ as catalyst in similar yield and selectivity than on a smaller scale, thus demonstrating the practicality of this process (Scheme 2).

Reaction could be further extended to the synthesis of polycyclic structures using cyclic enecarbamates and, tetrahydro-11a $H$-benzo[a]carbazol-11a-amide (6a) was obtained from the corresponding benzyl $(3,4-$ dihydronaphthalen-1-yl)carbamate (5a) and Boc-protected quinone diimine 1f (Scheme 3). Refinement of reaction conditions, namely using 2.0 eq of Boc quinone diimide under otherwise identical settings, significantly improved the outcome of the reaction furnishing the desired product as a single diastereoisomer in $85 \%$ yield and $80 \%$ ee. Cyclic acetamides $^{7 \mathrm{e}, 17}$ derived from dihydronaphthalene, indene and $2 \mathrm{H}$-chromene behaved particularly well in the transformation, furnishing compound $\mathbf{6 b}, \mathbf{6 d}$ and $\mathbf{6} \mathbf{f}$ in yields ranging from 82 to $96 \%$, each time as a single diastereoisomer and with near perfect enantioselectivity $(\geq 99 \%)$. Presence of a ring-fusion in acetamides seems to be an important factor to achieve high enantioselectivity. Indeed, while $N$-(cyclohex-1-en-1yl)acetamide allowed the synthesis of compound $\mathbf{6 e}$ in excellent yield, only modest enantioselectivity was observed in this case. Achieving the synthesis of highly enantio-enriched adduct $\mathbf{6 c}$ from methyl substituted Boc-quinone diimine, albeit in modest yield, is noteworthy since substitution on monoimide quinoids is reported to hamper reactivity. ${ }^{7 \mathrm{e}}$ Initial evaluation of tosylprotected quinone diimine 1a with cyclic enamide was sluggish and long. Solubility issue was identified as the main problem, and upon simple dilution ( $\mathrm{x} 4), \mathbf{6 g}$ could be isolated in satisfying yield. Furthermore, less reactive cyclic enethiourea ${ }^{13 b}$ could also react with Boc quinone diimide to form a single diastereomer $\mathbf{6 h}$ with excellent diastereoselectivity albeit with modest yield and enantioselectivity. Finally, the 7-membered cyclic enamide 5g was successfully employed in the present reaction, affording the expected cycloadduct $6 \mathbf{i}$ in $94 \%$ yield with $3: 1 \mathrm{dr}$ and $76 \%$ ee.

Scheme 3. Enantioselective $(3+2)$ formal cycloaddition with cyclic enes. $^{a-d}$
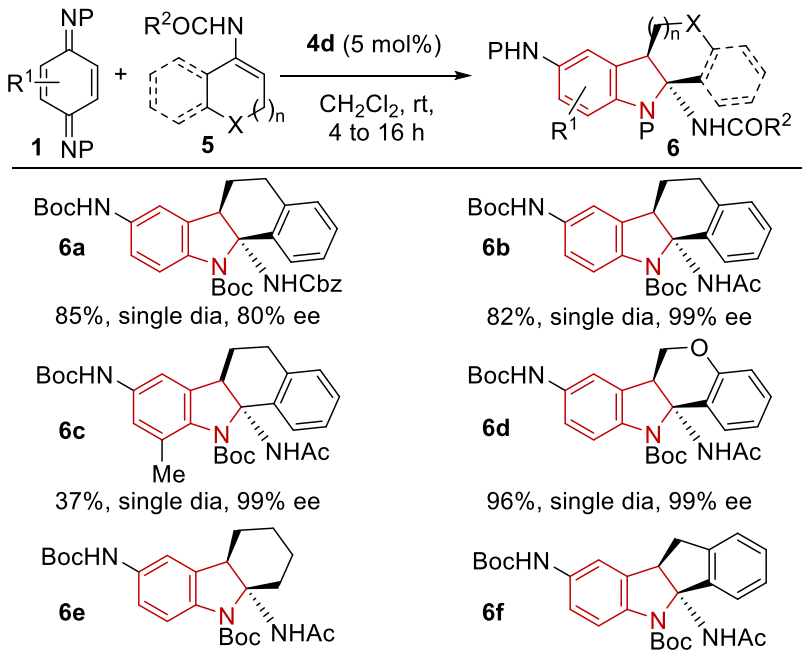

$96 \%$, single dia, $99 \%$ ee

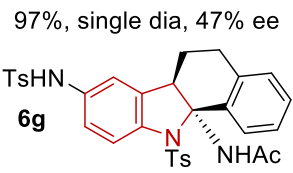

$56 \%$, single dia, $97 \%$ ee

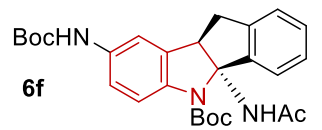

$84 \%$, single dia, $>99 \%$ ee
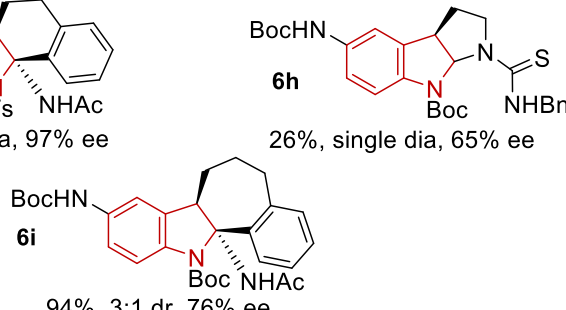

$26 \%$, single dia, $65 \%$ ee

$94 \%, 3: 1 \mathrm{dr}, 76 \%$

\footnotetext{
${ }^{a}$ General condition: $1(0.10 \mathrm{mmol}), 5(0.20 \mathrm{mmol})$ and $\mathbf{4 d}(5 \mathrm{~mol} \%)$ in $\mathrm{CH}_{2} \mathrm{Cl}_{2}(0.1 \mathrm{M})$ at $\mathrm{rt}$ for $16 \mathrm{~h} .{ }^{b}$ Yield of isolated pure product after column chromatography. ${ }^{c}$ ee Determined by HPLC analysis on a chiral stationary phase. ${ }^{d}$ dr determined by ${ }^{1} \mathrm{H}$ NMR.
} 
Scheme 4. Chemoselectivity of the enantioselective $(3+2)$ formal cycloaddition. ${ }^{a-d}$

a)

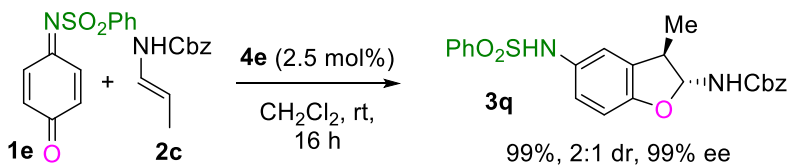

b)
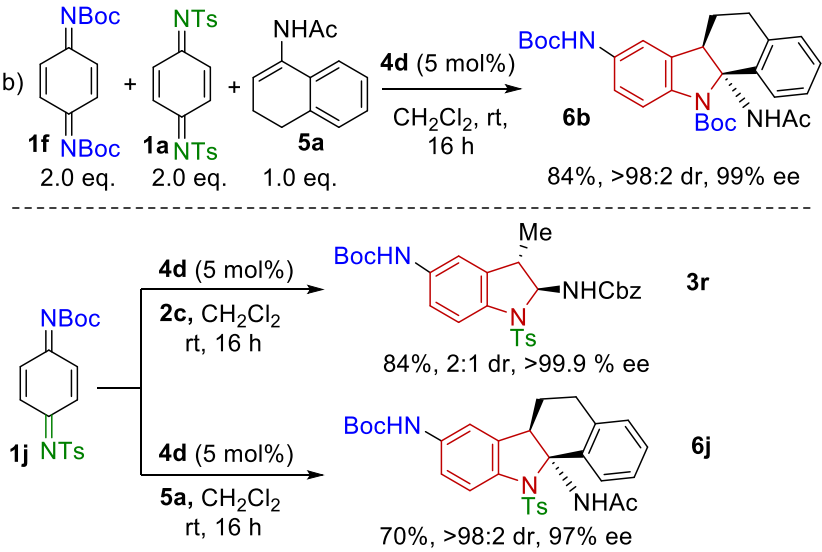

$3 r$

6j

As we could expect, the dihydrofuran $\mathbf{3 q}$ was obtained as sole regioisomer when reacting quinone monoimine 1e with enecarbamate 2c (Scheme 4, a), ${ }^{7 b-d}$ Complete selectivity was also observed when opposing an equal amount of bis-Boc and bis-tosyl protected imines (1f, 1a) to a limiting amount of cyclic enamide 5a, furnishing exclusively compound $\mathbf{6 b}$ (Scheme 4, b). Such a selectivity was not a simple consequence of solubility and could be further exploited for the selective synthesis of hetero protected compound $\mathbf{3 r}$ and $\mathbf{6 i}$ from the single hetero protected quinone diimine $\mathbf{1 j}$. While higher azaphilicity of phosphoric acids compared to oxaphilicity is wellknown, ${ }^{7 b, d, e, 13 e}$ these results also establish a relative affinity of such catalyst to differently $N$-protected species. To the best of our knowledge, it represents the first example in which CPAs were able to differentiate two common nitrogen protecting groups in enantioselective reaction.

Based on our ${ }^{7 \mathrm{a}}$ and other works, ${ }^{7 \mathrm{~b}, \mathrm{~d}, \mathrm{e}}$ a possible mechanism (Scheme 5) can be proposed, comprising the following steps: Michael addition, isomerization and intramolecular aminalization. This stepwise process is supported by the observation in the crude ${ }^{1} \mathrm{H}$ NMR spectra of aldehyde traces arising from hydrolyzed imine intermediate 6 . Then, we became interested in pursuing control experiments to propose a possible stereochemical model. No reaction occurred when either acyclic or cyclic tertiary enecarbamates $(\mathbf{2 m}$ or $\mathbf{2 n}$, respectively) were employed as dipolarophile (Scheme 6). This suggests that the $\mathrm{NH}$ group of $\mathbf{2 / 6}$ plays a crucial role in the successful activation for the cycloaddition to proceed smoothly. In addition, the reaction of $\mathbf{1 a}$ with $\beta, \beta$-disubstituted enecarbamate 20 in the presence of $4 \mathbf{e}$ affords the corresponding cycloadduct $3 \mathrm{~s}$ in nearly racemic form. This result rules out the possibility that catalyst maintained a hydrogen-bond with imine intermediate $\mathbf{B}$ to control the asymmetric induction of the hemiaminal stereogenic center.

X-Ray diffraction of $\mathbf{3 c}$ allowed us to determine the absolute configuration of both diastereoisomers obtained with $(R)-\mathbf{4 d}$ catalyst. Trans-isomers with $(2 S, 3 S)$ configuration was assigned for the major diastereoisomer while the one of minor cis-isomer was found to be $(2 R, 3 S)$. Absolute configurations of $\mathbf{6 b}$ and $\mathbf{6 g}$ were also elucidated by X-ray analysis and found to be $(6 \mathrm{a} R, 11 \mathrm{a} S)$, thereby highlighting that protecting group did not change the sense of selectivity. Based on these results, two transition state model TS-A and TS-A' in which both substrates are activated at the same time by the catalyst, with the formation of a double hydrogen bonding, can be proposed. According to Goodman's proposal, ${ }^{18}$ electrophiles and nucleophiles can be placed following type I or type II arrangement. However, minimizing steric clash with geometrically defined enes and keeping in mind that reacting centers of the nucleophile and the electrophile must be in close proximity for reactivity, allows building two favorable arrangement of type I. (see also supporting information). As such, the acyclic enecarbamate would attack from quinone diimide $R e$-face, while cyclic derivative would attack from their $S i$-face using $(R)-\mathbf{4 d}$. Following a possible partial decomplexation, tautomerization would lead to intermediate $\mathbf{B} / \mathbf{B}^{\prime}$ in which aniline would attack the acyl iminium leading to final compound.

Scheme 5. Plausible reaction mechanism.
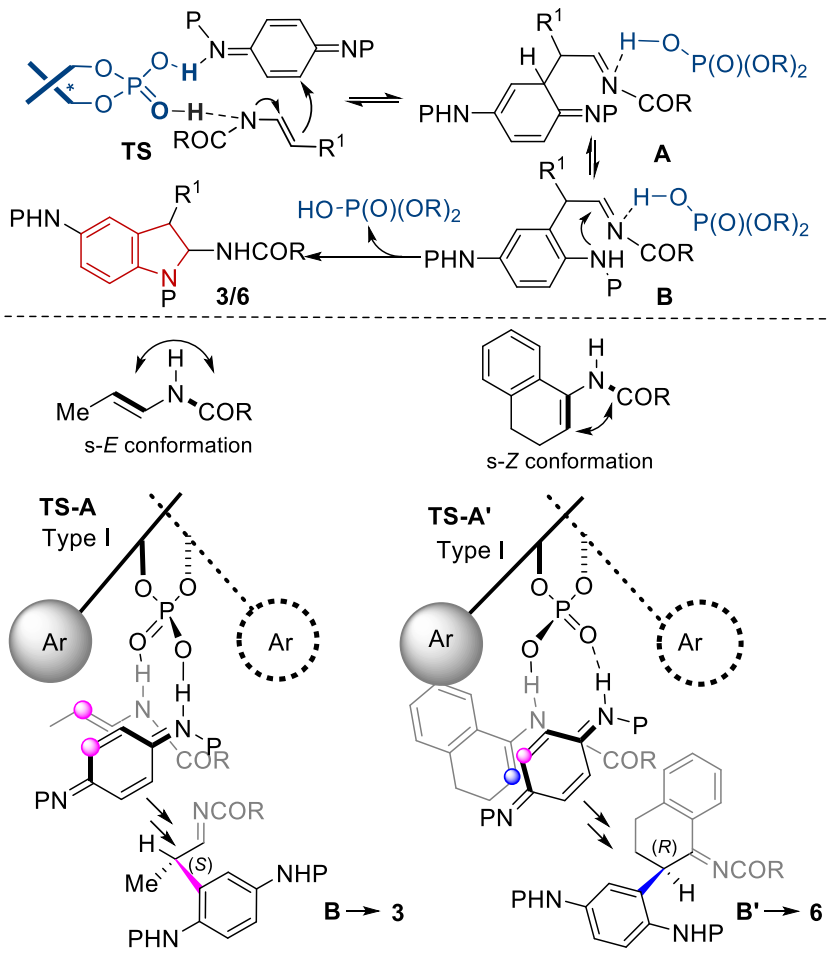

Scheme 6. Control experiments and further transformations.

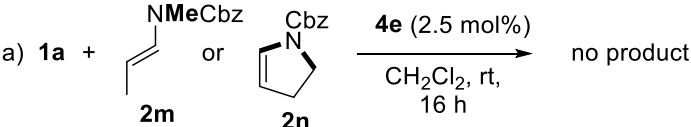

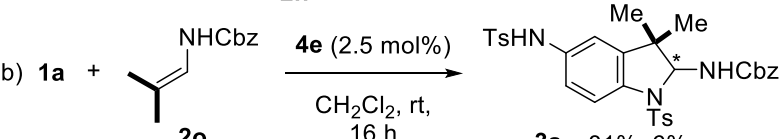
$20 \quad 36 \mathrm{~h} \quad 81 \%, 6 \%$ ee

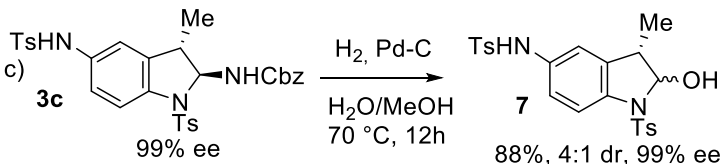


Interestingly, selective deprotection $\mathrm{Cbz}$ group could be achieved. Indeed; hydrogenation of $3 \mathbf{c}$ with $\mathrm{Pd}-\mathrm{C}$ at $70^{\circ} \mathrm{C}$ in a mixture $\mathrm{H}_{2} \mathrm{O} / \mathrm{MeOH}$ solvent gave hemiaminal 7 in good yield with complete retention of enantioselectivity (Scheme 6).

To conclude, we have successfully developed the first enantioselective $(3+2)$ cycloaddition of quinones diimides with $\beta$ substituted ene- and thioenecarbamates and with cyclic enamides using CPA catalysis. In addition, our work established the ability of phosphoric acid to differentiate selected nitrogen based on their individual protecting group. As such various indolines were obtained regio- and chemoselectively; and, in each case, with excellent yields and enantioselectivities.

\section{ASSOCIATED CONTENT}

\section{Supporting Information}

The Supporting Information is available free of charge at https://pubs.acs.org/doi/...

Experimental procedures, compound characterization data, $1 \mathrm{H}$, 13C, spectra and HPLC traces for all new compounds reported, and $\mathrm{X}$-ray data for compound $3 \mathrm{c}, 6 \mathrm{~b}$ and $6 \mathrm{~g}$ (PDF).

\section{Accession Codes}

CCDC 2016631, 2039802 and 2046101 contains the supplementary crystallographic data for this paper. These data can be obtained free of charge via from the Cambridge Crystallographic Data Centre via www.ccdc.cam.ac.uk/data_request/cif.

\section{AUTHOR INFORMATION}

\section{Corresponding Author}

Géraldine Masson, Institut de Chimie des Substances Naturelles, CNRS UPR 2301, Université Paris-Saclay, 91198 Gif-sur-Yvette Cedex, France. https://orcid.org/0000-0003-2333-7047, E-mail: geraldine.masson@enrs.fr

\section{Other Authors}

Wei-Yang Ma, Institut de Chimie des Substances Naturelles, CNRS UPR 2301, Université Paris-Saclay, Gif-sur-Yvette, France. Coralie Gelis, Institut de Chimie des Substances Naturelles, CNRS UPR 2301, Université Paris-Saclay, Gif-sur-Yvette, France.

Damien Bouchet, Institut de Chimie des Substances Naturelles, CNRS UPR 2301, Université Paris-Saclay, Gif-sur-Yvette, France. Pascal Retailleau, Institut de Chimie des Substances Naturelles, CNRS UPR 2301, Université Paris-Saclay, Gif-sur-Yvette, France. Xavier Moreau, Institut Lavoisier Versailles, UMR CNRS 8180, Université de Versailles-St-Quentin-en-Yvelines, Université ParisSaclay, Versailles, France. http://orcid.org/0000-0002-6737-9671. Luc Neuville Institut de Chimie des Substances Naturelles, CNRS UPR 2301, Université Paris-Saclay, Gif-sur-Yvette, France. https://orcid.org/0000-0002-4648-2469.

\section{Author Contribution}

\$W.-Y. Ma and C. Gelis contributed equally.

\section{Note}

The authors declare no competing financial interest.

\section{ACKNOWLEDGMENT}

We thank ICSN for financial support. W-YM thanks China Scholarship Council for the doctoral fellowship. CG thank ParisSaclay University for the doctoral fellowship. DB thanks CHARMMMAT LabEx for the master fellowship.

\section{REFERENCES}

(1) Seleted review: (a) Candeias, N. R.; Branco, L. C.; Goi, P. M. P.; Afonso, C. A. M.; Trindade, A. F. More Sustainable Approaches for the Synthesis of N-Based Heterocycles, Chem. Rev. 2009, 109, 2703. (b) Liu, D., Zhao, G.; Xiang, L. Diverse Strategies for the Synthesis of the Indoline Scaffold. Eur. J. Org. Chem. 2010, 3975. (c) Zhang, D.; Song, H.; Qin, Y. Total Synthesis of Indoline Alkaloids: A Cyclopropanation Strategy. Acc. Chem. Res. 2011, 44, 447. (d). Silva, T. S.; Rodrigues, M. T.; Santos, H.; Zeoly, L. A.; Almeida, W. P.; Barcelos, R. C.; Gomes, R. C.; Fernandes, F. S.; Coelho, F. Recent Advances in Indoline Synthesis. Tetrahedron, 2019, 75, 2063.

(2) (a) Rakhit, A.; Hurley, M. E.; Tipnis, V.; Coleman, J.; Rommel, A.; Brunner, H. R. Pharmacokinetics and Pharmacodynamics of Pentopril, a New Angiotensin-Converting-Enzyme Inhibitor in Humans. J. Clin. Pharmacol. 1986, 26, 156. (b) Poondra, R. R.; Kumar, N. N.; Bijian, K. K.; Prakesch, M.; Campagna-Slater, V.; Reayi, A.; Reddy, P. T.; Choudhry, A.; Barnes, M. L.; Leek, D. M.; Daroszewska, M.; Lougheed, C.; Xu, B.; Schapira, M.; Alaoui-Jamali, M. A.; Arya, P. Discovery of Indoline-Based, Natural-Product-like Compounds as Probes of Focal Adhesion Kinase Signaling Pathways. J. Comb. Chem. 2009, 11, 303. (c) Wilson, J. E.; Kurukulasuriya, R.; Reibarkh, M.; Reiter, M.; Zwicker, A.; Zhao, K.; Zhang, F.; Anand, R.; Colandrea, V. J.; Cumiskey, A. M.; Crespo, A.; Duffy, R. A.; Murphy, B. A.; Mitra, K.; Johns, Duffy, J. L.; Vachal, P. ACS Med. Chem. Lett. 2016, 7, 261.

(3) Selected examples: (a) Kunz, R. K.; MacMillan, D. W. C. Enantioselective Organocatalytic Cyclopropanations. The Identification of a New Class of Iminium Catalyst Based upon Directed Electrostatic Activation. J. Am. Chem. Soc. 2005, 127, 3240. (b) Andersson, F.; Hedenström, E. Synthesis of two (S)-Indoline-Based Chiral Auxiliaries and Their Use in Diastereoselective Alkylation Reactions. Tetrahedron: Asymmetry 2006, 17, 1952. (c) Hartikka, A.; Arvidsson, P. I. Tetrazolic Acid Functionalized Dihydroindol: Rational Design of a Highly Selective Cyclopropanation Organocatalyst. J. Org. Chem. 2007, 72, 5874 and references therein.

(4) (a) Arp, F. O.; Fu, G. C. Kinetic Resolutions of Indolines by a Nonenzymatic Acylation Catalyst. J. Am. Chem. Soc. 2006, 128, 14264. (b) López-Iglesias, M.; Busto, E.; Gotor, V.; Gotor-Fernández, V. Stereoselective Synthesis of 2,3-Disubstituted Indolines Diastereoisomers by Chemoenzymatic Processes. J. Org. Chem. 2012, 77, 8049. (c) Cai, Q.; You, S.-L. Organocatalyzed Enantioselective Formal [4 + 2] Cycloaddition of 2,3-Disubstituted Indole and Methyl Vinyl Ketone. Org. Lett. 2012, 14, 3040. (d) Yin, Q.; You, S.-L. Asymmetric Chlorocyclization of Indole-3-yl-benzamides for the Construction of Fused Indolines. Org. Lett. 2014, 16, 2426. (e) Panda, S.; Ready, J. M. Tandem Allylation/1,2-Boronate Rearrangement for the Asymmetric Synthesis of Indolines with Adjacent Quaternary Stereocenters. J. Am. Chem. Soc. 2018, 140, 13242. (f) Pirovano,V.; Brambilla, E.; Tseberlidis, G. [Copper(I)(Pyridine-Containing Ligand)] Catalyzed Regio- and Steroselective Synthesis of 2-Vinylcyclopropa[b]indolines from 2-Vinylindoles. Org. Lett. 2018, 20, 405. (g) Kuang, X.-K.; Zhu, J.; Zhou, L.; Wang, L.; Wang, S. R; Tang, Y. Synergetic Tandem Enantiomeric Enrichment in Catalytic Asymmetric Multi-Component Reactions (AMCRs): Highly Enantioselective Construction of Tetracyclic Indolines with Four Continuous Stereocenters. ACS Catal. 2018, 8, 4991. Recent Selected Asymmetric dearomatisation: (h) Daniels, B. E.; Ni, J.; Reisman, S. E. Synthesis of Enantioenriched Indolines by a Conjugate Addition/Asymmetric Protonation/Aza-Prins Cascade Reaction. Angew. Chem. Int. Ed. 2016, 55, 3398. (i) Jing, C.; Cheng, Q.-Q.; Deng, Y.; Arman, H.; Doyle, M. P. Highly Regio- and Enantioselective Formal [3 + 2]-Annulation of Indoles with Electrophilic Enol Carbene Intermediates. Org. Lett. 2016, 18, 4550. (j) Zhu, Y.; He, W.; Wang, W.; Pitsch, C. E.; Wang, X, Wang, X. Enantioselective Tandem Cyclization of Alkyne-Tethered Indoles Using Cooperative Silver(I)/Chiral Phosphoric Acid Catalysis. Angew. Chem. Int. Ed. 2017, 56, 12206. (k) Li, T.-R.; Lu, L.-Q.; Wang, Y.-N.; Wang, B-C.; Xiao, W-J. Divergent Synthesis of Polycyclic Indolines: CopperCatalyzed Cascade Reactions of Propargylic Carbamates and Indoles. Org. Lett. 2017, 19, 4098. (1) Fang, X.; Gao, S.; Wu, Z.; Yao, H. Lin, A. Pd(II)-Catalyzed Oxidative Dearomatization of Indoles: SubstrateControlled Synthesis of Indolines and Indolones. Org. Chem. Front. 2017, 4, 292. (m) Shi, Y.; Gao, Q.; Xu, S. NHC-Copper-Catalyzed 
Asymmetric Dearomative Silylation of Indoles. J. Org. Chem. 2018, 83, 14758. (n) Gao, R.-D.; Ding, L.; Zheng, C.; Dai, L.-X.; You, S.-L. Palladium(0)-Catalyzed Intermolecular Asymmetric Allylic Dearomatization of Polycyclic Indoles. Org. Lett. 2018, 20, 748. (o) Trost, B. M.; Bai, W.-J.; Hohn, C.; Bai, Y.; Cregg, J. J. PalladiumCatalyzed Asymmetric Allylic Alkylation of 3-Substituted 1H-Indoles and Tryptophan Derivatives with Vinylcyclopropanes. J. Am. Chem. Soc. 2018, 140, 6710. (p) Zhang, J-Q.; Tong, F.; Sun, B.-B.; Fan, W.T.; Chen, J.-B.; Hu, D.; Wang, X.-W. Pd-Catalyzed Asymmetric Dearomative Cycloaddition for Construction of Optically Active Pyrroloindoline and Cyclopentaindoline Derivatives: Access to 3aAminopyrroloindolines. J. Org. Chem. 2018, 83, 2882. (q) Zhang, H.J.; Gu, Q.; You, S.-L. Ni-Catalyzed Intermolecular Allylic Dearomatization Reaction of Tryptophols and Tryptamines. Org. Lett. 2019, 21, 9420. (r) Yu, Q.; Fu, Y.; Huang, J.; Qin, J.; Zuo, H.; Wu, Y.; Zhong, Y. Enantioselective Oxidative Phenol-Indole [3+2] Coupling Enabled by Biomimetic Mn(III)/Brønsted Acid Relay Catalysis. ACS Catal. 2019, 9, 7285. Recent enantioselective cyclization: (s) Wang, Q.; Li, T.-R.; Lu, L.-Q.; Li, M.-M., Zhang, K.; Xiao, W.-J.Catalytic Asymmetric $[4+1]$ Annulation of Sulfur Ylides with Copper-Allenylidene Intermediates, J. Am. Chem. Soc. 2016, 138, 8360. (t) Chen, S.-S.; Meng, J. Li, Y.-H.; Han, Z. Y. PalladiumCatalyzed Enantioselective Heteroannulation of 1,3-Dienes by Functionally Substituted Aryl Iodides. J. Org. Chem. 2016, 81, 9402. (u) Zhu, D.; Ma, J.; Luo, K.; Fu, H.; Zhang, L.; Zhu, S. Enantioselective Intramolecular C-H Insertion of Donor and Donor/ Donor Carbenes by a Nondiazo Approach. Angew. Chem. Int. Ed. 2016, 55, 8452. (v) Yang, L.; Melot, R.; Neuburger, M.; Baudoin, O. Palladium(0)-Catalyzed Asymmetric C(sp3)-H Arylation Using a Chiral Binol-derived Phosphate and an Achiral Ligand. Chem. Sci. 2017, 8, 1344. (w) Yu, S.-N.; Li, Y.-L.; Deng, J. Enantioselective Synthesis of 2-Bromomethyl Indolines via BINAP(S)-Catalyzed Bromoaminocyclization of Allyl Aniline. Adv. Synth. Catal. 2017, 359, 2499. (x) Reddy, N.; Reddy, V. R.; Dinda, S. Nanubolu, J. B.; Chandra, R. Asymmetric Reaction of p-Quinone Diimide: Organocatalyzed Michael Addition of $\alpha$-Cyanoacetates Sivakumar. Org. Lett. 2018, 20, 2572. (y) Yang, J.; Ke, C.; Zhang, D.; Liu, X.; Feng, X. Enantioselective Synthesis of 2,2,3-Trisubstituted Indolines via Bimetallic Relay Catalysis of $\alpha$-Diazoketones with Enones. Org. Lett. 2018, 20, 4536. (z) Zhang, G.; Cang, A.; Wang, Y.; Li, Y.; Xu, G.; Zhang, Q.; Xiong, T.; Zhang, Q. Copper-Catalyzed Diastereo- and Enantioselective Borylative Cyclization: Synthesis of Enantioenriched 2,3-Disubstituted Indolines. Org. Lett. 2018, 20, 1798. (aa) Souza, L. W.; Squitieri, R. A.; Dimirjian, C. A.; Hodur, B. M.; Nickerson, L. A.; Penrod, C. N.; Cordova, J.; Fettinger, J. C.; Shaw, J. T. Enantioselective Synthesis of Indolines, Benzodihydrothiophenes, and Indanes by $\mathrm{C}-\mathrm{H}$ Insertion of Donor/Donor Carbenes. Angew. Chem. Int. Ed. 2018, 57, 15213. (ab) Tian, Z.-X.; Qiao, J.-B.; Xu, G.-L.; Pang, X.; Qi, L.; Ma, W.-Y.; Zhao, Z.-Z.; Duan, J. Du, Y.-F.; Su, P.; Liu, X.-Y.; Shu, X.-Z.; Highly Enantioselective Cross-Electrophile Aryl-Alkenylation of Unactivated Alkenes. J. Am. Chem. Soc. 2019, 141, 7637. (ac) Xu, C.; Feng, Y.; Li, F.; Han, J. He, Y.-M., Fan, Q.-H. A Synthetic Route to Chiral BenzoFused N-Heterocycles via Sequential Intramolecular Hydroamination and Asymmetric Hydrogenation of Anilino-Alkynes. Organometallics 2019, 38, 3979. (ad) Ping, Y.; Wang, K.; Pan, Q.; Ding, Z.; Zhou, Z.; Guo, Y.; Kong, W. Ni-Catalyzed Regio- and Enantioselective Domino Reductive Cyclization: One-Pot Synthesis of 2,3-Fused Cyclopentannulated Indolines ACS Catal. 2019, 9, 7335. (ae) Zhang, Z.M.; Xu, B.; Wu, L.; Zhou, L.; Ji, D.; Liu, Y. Li, Z. Zhang, J. Palladium/XuPhos-Catalyzed Enantioselective Carboiodination of Olefin-Tethered. J. Am. Chem. Soc. 2019, 141, 8110. Selected recent Reduction: (af) Yang, Z.; Chen, F.; He, Y.; Yang, N.; Fan, Q.-H. Highly Enantioselective Synthesis of Indolines: Asymmetric Hydrogenation at Ambient Temperature and Pressure with Cationic Ruthenium Diamine Catalysts. Angew. Chem. Int. Ed. 2016, 55, 13863. (ag) Touge, T.; Arai, T. Asymmetric Hydrogenation of Unprotected Indoles Catalyzed by $\eta 6-$ Arene/N-Me-sulfonyldiamine- $\mathrm{Ru}(\mathrm{II})$ Complexes. J. Am. Chem. Soc. 2016, 138, 11299. (ah) Wen, J. Fan, X.; Tan, R. Chien, H.-C.; Zhou, Q.; Chung, L. W.; Zhang, X. BrønstedAcid-Promoted Rh-Catalyzed Asymmetric Hydrogenation of
N-Unprotected Indoles: A Cocatalysis of Transition Metal and Anion Binding. Org. Lett. 2018, 20, 2143.

(5) Reviews (a) Moyano, A.; Rios, R. Asymmetric Organocatalytic Cyclization and Cycloaddition Reactions. Chem. Rev. 2011, 111, 4703. (b) DeEun, N.; Yoo, J. Recent Advances in the Catalytic Cycloaddition of 1,n-Dipoles. ACS Catal. 2018, 8, 48.

(6) For reviews, see: (a) Bertolini, F.; Pineschi, M. Recent Progress in the Synthesis of 2,3-Dihydrobenzofurans. Org. Prep. Proced. Int. 2009, 41, 385. (b) Sheppard, T. D. Strategies for the Synthesis of 2,3Dihydrobenzofurans. J. Chem. Res. 2011, 377. For selected examples, see: (c) Engler, T. A.; Chai, W.; Lynch, K. O. Switchable Regioselectivity in Lewis Acid-promoted Reactions of 1,4Benzoquinone Monoimides with Styrenyl Systems: Selective Syntheses of either 2-Aryl-2,3-dihydrobenzofurans or 2-Aryl-2,3dihydroindoles. Tetrahedron Lett. 1995, 36, 7003. (d) Engler, T. A.; Chai, W. K.; LaTessa, O. Lewis Acid-Controlled Regioselectivity in Reactions of Styrenyl Systems with Benzoquinone Monoimides: New Regioselective Syntheses of Substituted 2-Aryl-2,3dihydrobenzofurans, 2-Aryl-2,3-dihydroindoles, and 2-Arylindoles. $J$. Org. Chem. 1996, 61, 9297. (e) Lomberget, T.; Baragona, F.; Fenet, B.; Barret, R. [3+2] versus [4+2] Cycloadditions of Quinone Monoimide with Azadienes: A Lewis Acid-Free Access to 5-Amino-2,3dihydrobenzofuranes. Org. Lett. 2006, 8, 3919. (f) Fan, R.; Li, W.; Ye, Y.; Wang, L. One-Pot Oxidative Heteroannulations of $\mathrm{N}$ Sulfonylanilines with Styrenes for the Construction of 5Aminocoumaran Derivative. Adv. Synth. Catal. 2008, 350, 1531. (g) Baragona, F.; Lomberget, T.; Duchamp, C.; Henriques, N.; Lo Piccolo, E.; Diana, P.; Montalbano, A.; Barret, R. Synthesis of 5-Substituted 2,3-Dihydrobenzofurans in a one-pot Oxidation/Cyclization Reaction. Tetrahedron 2011, 67, 8731.

(7) Enantioselective [3+2] cycloaddition with quinones: (a) Gelis, C.; Bekkaye, M.; Lebée, C.; Blanchard, F.; Masson, G. Chiral Phosphoric Acid Catalyzed [3 +2$]$ Cycloaddition and Tandem Oxidative [3 + 2] Cycloaddition: Asymmetric Synthesis of Substituted 3-Aminodihydrobenzofurans. Org. Lett. 2016, 18, 3422. Enantioselective [3+2] cycloadditions with quinone-monoimines: (b) Jensen, K. L.; Franke, P. T.; Nielsen, L. T.; Daasbjerg, K.; Jørgensen, K. A. Angew. Chem. Int. Ed. 2010, 49, 129. (c) Hashimoto, T.; Nakatsu, H.; Takiguchi, Y.; Maruoka, K. Axially Chiral Dicarboxylic Acid Catalyzed Activation of Quinone Imine Ketals: Enantioselective Arylation of Enecarbamates. J. Am. Chem. Soc. 2013, 135, 16010. (d) Sun, X.-X.; Zhang, H.-H.; Li, G.-H.; Menga, L.; Shi, F. Diastereo- and Enantioselective Construction of an Indole-based 2,3Dihydrobenzofuran Scaffold via Catalytic Asymmetric [3+2] Cyclizations of Quinone Monoimides with 3-Vinylindoles Chem. Commun. 2016, 52, 2968. (e) Zhang, M.; Yu, S.; Hu, F.; Liao, Y.; Liao, L. Xu, X.; Yuan, W.; Zhang, X. Highly Enantioselective [3+2] Coupling of Cyclic enamides with Quinone Monoimines Promoted by a Chiral Phosphoric Acid. Chem. Commun. 2016, 52, 8757.

(8) (a) Domschke, G.; Heller, G.; Natzeck, U. Über die Einwirkung von Enaminen auf Chinone, VII. Darstellung von substituierten 5Amino-indolen. Chem. Ber. 1966, 99, 939. (b) Takahata, H. Anazawa, A.; Moriyama, K.; Yamazaki, T. Ketene S,N-Acetals as Synthetic Intermediates for Heterocycles. Reaction of Ketene S,N-Acetals with 1,4-Quinones. J. Chem. Soc. Perkin Trans. I 1987, 1501. (c) Mukaiyama, T.; Sagawa, Y.; Kobayashi, S. The Michael Reaction of Various Quinones with Silyl Enol Ethers. A Facile method for the Preparation of Benzofuran and Indole Derivatives. Chem. Lett. 1987, 2169. (d) Boger, D. L.; Zarrinmayeh, H. Regiocontrolled Nucleophilic Addition to Selectively Activated p-Quinone Diimines: Alternative Preparation of a Key Intermediate Employed in the Preparation of the CC-1065 Left-hand Subunit. J. Org. Chem. 1990, 55, 1379. (e) Nair, V.; Rajesh, C.; Dhanya, R.; Rath, N. P. Lewis Acid Promoted Annulation of $p$-Quinoneimines by Allylsilanes: A Facile Entry into Benzofused Heterocycles. Org. Lett. 2002, 4, 953. (f) Wang, Q.; Wang, P.; Gao, X.; Wang, D.; Wang, S.; Liang, X.; Wang, L; Zhang, H.; Lei, A. Regioselective/Electro-oxidative Intermolecular [3+2] Annulation for the Preparation of Indolines. Chem. Sci. 2020, 11, 2181.

(9) Nair, V.; Dhanya, R.; Rajesh, C.; Devipriya, S. Recent Developments in the Chemistry of Quinoneimides. Synlett, 2005, 2407. 
(10) Miyagi, Y.; Banjyo, N.; Yamamura, E. The Facile Oxidative Coupling of a Hindered Phenol, 2,6-Di-t-butyl-phenol, Driven by $N, N$ 'Bis(ethoxy-carbonyl)-1,4-benzoquinone Diamine. Bull. Chem. Soc. Jpn. 2002, 75, 857.

(11) Nair, V.; Dhanya, R.; Rajesh, C.; Devipriya, S. Recent Developments in the Chemistry of Quinoneimides. Synlett, 2005, 2407.

(12) With o-diimides : Abraham, C. J.; Paull, D. H.; Scerba, M. T.; Grebinski, J. W.; Lectka, T. Catalytic, Enantioselective Bifunctional Inverse Electron Demand Hetero-Diels-Alder Reactions of Ketene Enolates and o-Benzoquinone Diimides. J. Am. Chem. Soc. 2006, 128, 13370.

(13) (a) He, L.; Bekkaye, M.; Retailleau, P.; Masson, G. Chiral Phosphoric Acid Catalyzed Inverse-Electron-Demand Aza-DielsAlder Reaction of Isoeugenol Derivatives. Org. Lett. 2012, 14, 3158. (b) Dagousset, G., Retailleau, P., Masson, G., Zhu, J. Chiral Phosphoric Acid-Catalyzed Enantioselective Three-Component Povarov Reaction Using Cyclic Enethioureas as Dienophiles: Stereocontrolled Access to Enantioenriched Hexahydropyrroloquinolines. Chem. Eur. J. 2012, 18 : 5869. (c) He, L.; Laurent, G.; Retailleau, P.; Folleas, B.; Brayer, J.-L.; Masson, G. Highly Enantioselective Aza-Diels-Alder Reaction of 1Azadienes with Enecarbamates Catalyzed by Chiral Phosphoric Acids. Angew. Chem., Int. Ed. 2013, 52, 11088. (d) J. Pous, T. Courant, G. Bernadat, B. I. Ioga, F. Blanchard, G. Masson, J. Am. Chem. Soc. 2015, 137, 11950. (e) Jarrige, L.; Blanchard, F.; Masson, G. Enantioselective Organocatalytic Intramolecular Aza-Diels-Alder Reaction. Angew. Chem., Int. Ed. 2017, 56, 10573. (f) Gelis, C.; Levitre, G.; Merad, J.; Retailleau, P.; Neuville, L., Masson, G. Highly Diastereo- and Enantioselective Synthesis of Cyclohepta[b]indoles by ChiralPhosphoric-Acid-Catalyzed (4+3) Cycloaddition. Angew. Chem., Int. Ed. 2018, 57, 12121. (g) Jarrige, L.; Glavač, D.; Levitre, G.; Retailleau, P.; Bernadat, G.; Neuville, L.; Masson, G. Chiral Phosphoric AcidCatalyzed Enantioselective Construction of Structurally Diverse Benzothiazolopyrimidines. Chem. Sci. 2019, 10, 3765.

(14) Recent reviews on chiral phosphoric acid catalysis: (a) Merad, J.; Lalli, C.; Bernadat, G.; Maury, J.; Masson, G. Enantioselective Brønsted Acid Catalysis as a Tool for the Synthesis of Natural Products and Pharmaceuticals. Chem. Eur. J. 2018, 24, 3925. (b) Parmar, D.; Sugiono, E.; Raja, S.; Rueping, M. Complete Field Guide to Asymmetric BINOL-Phosphate Derived Brønsted Acid and Metal Catalysis: History and Classification by Mode of Activation; Brønsted Acidity, Hydrogen Bonding, Ion Pairing, and Metal Phosphates. Chem. Rev. 2017, 117, 10608; Chem. Rev. 2014, 114, 9047. (c) Schenker, S.; Zamfir, A.; Freund, M.; Tsogoeva, S. B. Developments in Chiral Binaphthyl-Derived Brønsted/Lewis Acids and Hydrogen-BondDonor Organocatalysis. Eur. J. Org. Chem. 2011, 2209. (d) Rueping, M.; Kuenkel, A.; Atodiresei, I. Chiral Brønsted Acids in Enantioselective Carbonyl Activations - Activation Modes and Applications. Chem. Soc. Rev. 2011, 40, 4539. (e) Kampen, D.; Reisinger, C. M.; List, B. Chiral Brønsted Acids for Asymmetric Organocatalysis. Top. Curr. Chem. 2010, 291, 395. (f) Terada, M. Chiral Phosphoric Acids as Versatile Catalysts for Enantioselective Transformations. Synthesis 2010, 1929. (g) Akiyama, T. Stronger Brønsted Acids. Chem. Rev. 2007, 107, 5744.

(15) 8:1 dr did not change even after prolonged treatment with phosphoric acid in DCM indicating that the mixtures obtained don't result from a thermodynamically controlled process(see also the supporting information).

(16) Also not fully investigated, we observed that unsuitable reactive reagents are rapidly reduced back to their anilines precursor under the reactions condition, preventing reaction.

(17) (a) Kretzschmar, M.; Hodik, T.; Schneider, C. Brønsted acid catalyzed addition of enamides to ortho-quinone methide imines - an efficient and highly enantioselective synthesis of chiral tetrahydroacridines. Angew. Chem. Int. Ed. 2016, 55, 9788. b) Saha, S.; Schneider, C. Directing Group Assisted Nucleophilic Substitution of Propargylic Alcohols via o-Quinone Methide Intermediates: Brønsted Acid Catalyzed, Highly Enantio- and Diastereoselective Synthesis of 7-Alkynyl-12a-acetamido-substituted Benzoxanthenes. Org. Lett. 2015, 17, 648 .

(18) Reid, J.; Simon, L.; Goodman, J. A Practical Guide for Predicting the Stereochemistry of Bifunctional Phosphoric Acid Catalyzed Reactions of Imines. Acc. Chem. Res. 2016, 49, 1029. 